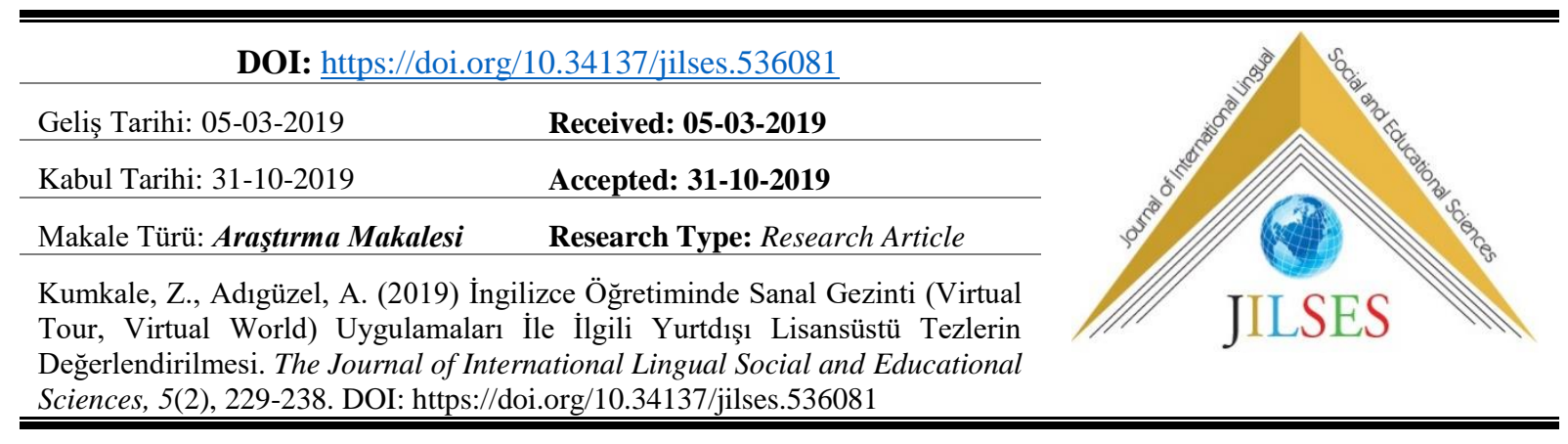

\title{
İngilizce Öğretiminde Sanal Gezinti (Virtual Tour, Virtual World) Uygulamaları İle İlgili Yurtdışı Lisansüstü Tezlerin Değerlendirilmesi
}

\section{Zeynep KUMKALE ${ }^{1}$ Abdullah ADIGÜZEL ${ }^{2}$}

$\ddot{\mathbf{O} z}$

Bu araştırmanın amacı, yurtdışında İngilizce öğretiminde sanal gezinti uygulamaları kullanımı üzerine yapılmış lisansüstü tezleri incelemek ve bu çalışmalardan elde edilen sonuçlar doğrultusunda İngilizce ögretiminde sanal gezinti uygulamalarıyla ilgili çeşitli öneriler sunmaktır. Bu nedenle araştırmada, 2008-2018 yılları arasında yurtdışında Ingilizce ögretiminde sanal gezinti uygulamaları kullanımı üzerine gerçekleştirilmiş lisansüstü tezlerin incelenerek değerlendirilmesi yapılmıştır. Çalışmada meta-sentez ve doküman incelemesi yöntemleri kullanılmıştır. Çalışmaların çoğunluğunda sanal gezinti uygulamaları olarak Second Life portalının kullanıldı̆̆ görülmüştür. Ingilizce öğretimi kapsamında yapılacak olan herhangi bir meta-sentez çalışması için farklı bilgisayar uygulamalarının da İngilizce öğretiminde kullanımının da incelenmesi gerekir. Ayrıca, Türkiye'de de İngilizce ögretiminde sanal uygulamaların kullanımının yaygınlaştırılması da etkili olacaktır.

Anahtar Kelimeler: İngilizce ögretimi, sanal gezinti, meta-sentez, doküman inceleme

\section{Evaluation of Foreign Postgraduate Theses on the Use of Virtual Tour (Virtual World) Applications on English Language Teaching}

\begin{abstract}
The aim of this study is to examine the foreign theses on the use of virtual tour applications in English language teaching and to present various suggestions about teaching English in line with the results obtained from these studies. For this reason, in the study, foreign postgraduate theses on the use of virtual tour applications in English teaching between the years 2008-2018 were examined and evaluated. Meta-synthesis and document analysis methods were used in the study. In the majority of studies, it was seen that the Second Life portal was used as virtual tour application. The use of different computer applications in the teaching of English for any meta-synthesis study to be conducted in the context of English teaching should also be examined. In addition, the adoption and use of virtual applications in the teaching of English in Turkey will also be effective.
\end{abstract}

Key words: English language teaching, virtual tour, meta-synthesis, document analysis

\footnotetext{
Doktora öğrencisi, Düzce Üniversitesi, Eğitim Programları ve Öğretim Bölümü, kumkalezeynep@gmail.com, http://orcid.org/0000-0003-4580-7441)

2 Prof. Dr., Düzce Üniversitesi, Eğitim Programları ve Öğretim Bölümü, aadgzel@ gmail.com, http://orcid.org/0000-00017184-3644)
} 


\section{Giriş}

Bilgisayar destekli dil öğretimi, bilgisayar destekli öğretim alanından ortaya çıkan yeni bir disiplindir (Warschauer ve Healey, 1998). Bu disiplin, çok boyutlu ortamlarda daha derinlemesine bir araştırma olanağı sağlamakla birlikte disiplinler arası bir yaklaşımla, yeni olarak görülen dil öğrenme çeşitlerinden bazılarını öğrenme ve öğretme çevrelerine tanıtmıştır (Yamazaki, 2015). Bilgisayar destekli dil öğretimi ilk olarak 1980'lerde (Chambers, 2010), bilgisayarlı oyun prototiplerini tanımlayan ve bu oyunların sınıf ortamında nasıl bir araya getirildiğini gösteren keşifsel bir yaklaşımdan ortaya çıkmıştır (Peterson, 2010). Farklı uzmanlarca önerilen bu bilgisayarlı oyun türleri arasında, simülasyon oyunu ve sanal gerçeklik (VR) büyük ilgi görmekle birlikte, bugün bilgisayar destekli dil öğretimi alanında önemli eğilimler haline gelmiştir (Ranalli, 2008; Coleman, 2002).

Henderson ve arkadaşları (2009) tarafından sanal dünya olarak da adlandırılan sanal gerçeklik, gerçek olmayan bir ortamda sanal bir çevrede kullanıcılara yanılsamayı veren bir bilgisayar teknolojisidir (Alfadil, 2017). McLellan, (2004) sanal gerçekliği, verilerle daha sezgisel etkileşime izin veren ve insani duyuları yeni şekillerde içeren, bilgisayar kontrollü çok duyulu iletişim teknolojilerinin bir sınıfı olarak tanımlamıştır. Stevenson ve Lindberg (2015) sanal gerçekliği "içerisinde ekrana sahip bir kask veya sensörler ile donatılmış eldivenler gibi özel elektronik teçhizat kullanan bir kişi tarafından gerçek veya fiziksel bir şekilde etkileşime girebilen üç boyutlu bir görüntünün veya ortamın bilgisayar tarafından oluşturulan simülasyonu” olarak açıklamışlardır. Diğer yandan Jacobson (1993), sanal bir dünyayı, kullanıcının mevcut hissettiği bir bilgisayar tarafından yaratılan bir ortam olarak tanımlar. Sanal gerçeklikler insanın, öznenin sanal ortamla etkileşime girebileceği gerçek bir durumun bilgisayar simülasyonudur, bu simülasyonlarda bazen sahnenin temsil edildiği gözlükler ve kasklar gibi konvansiyonel olmayan arabirim araçlarıyla sesler yeniden üretilir (Achille, vd., 2016).

Özellikle İngilizce öğretimi ile ilgili olarak, sanal dünyaların potansiyel faydalarını tartışan yeni bir alan yazın mevcuttur (Abal, 2013). Örneğin, Von Der Emde ve arkadaşları (2001), İngilizce öğretimi için sanal dünyaların, öğrencilere dil kullanımını kültür ve sosyal etkileşimin bir parçası olarak bağlamsallaştırma yeteneği sağladığını ileri sürmüştür. Yapılan araştırmalar, sanal topluluklardaki etkileşimli etkinliklerle, İngilizce öğrenenlerin çoklu öğrenme uygulamalarına girerken kimliklerini oluşturabileceğini göstermektedir (Black, 2005; Lam, 2000; Yi, 2008). Sanal gerçeklik, eğitimciler için öğrencilere yapılandırmacı öğrenme etkinlikleri uygulayabilecekleri bir öğrenim ortamına yerleştirmede eşsiz bir firsat sunmaktadır (Dickey, 2005). Deutschmann ve arkadaşları (2009) bu etkileşimli ortamın sağladığı sürükleyici deneyimin, daha önce eğitimciler için bir seçenek olmadığını ve öğrenci performansını, devamlılığını ve motivasyonunu geliştirmek için firsatlar sunduğunu belirtmişlerdir. Sanal bir dünyanın kullanımı, günümüzün teknoloji merkezli dünyasında, İngilizce sınıflarında potansiyeli gösteren bir araçtır (Gump, 2015). Henderson ve arkadaşları (2012) yapmış oldukları bir çalışmalarında İngilizce öğrenmede sanal dünyaların "etkin filtre, kalıcı ortamlar ve kayıtlar, bedensel ve dilsel işbirliği, avatar kontrolü ve öğrenci özerkliği, sanal dünya deneyiminde bile metin etkileşimlerinin değeri, aracı ortam, içeriğe duyarlı etkileşimler ve beden dili" olmak üzere sekiz ayrı kolaylık sağladığını belirtmişlerdir. Ayrıca, bu kolaylıklar bireyin internete bağlı aygıtının rahatlığıyla, herhangi bir yere fiziksel olarak gitme ihtiyacı olmadan gerçekleştirilebilir ve yabancı dil öğrenenler için bireysel, otantik ve özerk dil öğrenme deneyimi olabilir (Von Der Emde vd., 2001).

Carruthers (2013) sanal dünyaların, birçok farklı alanda eğitim potansiyelleri için geniş çapta araştırılmış ve araştırılan güncel ve yenilikçi platformlar olduğundan ancak dil öğretiminde kullanılan sanal ortamlar üzerine yapılan araştırmaların sınırlı olduğundan söz etmektedir. Yukarıda belirtilenlere ek olarak alan yazın incelendiğinde, sanal gezintilerin İngilizce öğrenenlerin konuşma becerileri ve dil gelişimleri üzerindeki yararları ve etkilerini belirten çok az sayıda deneysel çalışma vardır (Garcia-Ruiz vd., 2007; Ranalli, 2008; Zheng vd., 2009). Az sayıdaki mevcut çalışmalardan, sanal ortamların geliştirilmiş bir öğrenme ortamı sağladığı bulunmuştur (Barkand ve Kush, 2009; Peterson, 2006; Zheng vd., 2009). Ülkemizde de İngilizce öğretiminde sanal gezinti uygulamaları üzerine yapılan çalışma sayısı oldukça kısıtlıdır. Bu nedenle, bu çalışma İngilizce öğretiminde sanal gezinti uygulamalarının kullanımının dil öğretimine olan etkilerini çeşitli değişkenler açısından incelemeyi konu edinmesi bakımından önemlidir.

\section{Araştırmanın Amacı}

$\mathrm{Bu}$ çalışmanın genel amacı yurt dışında İngilizce öğretiminde sanal gezinti uygulamalarının kullanımını konu edinen lisansüstü tez çalışmalarını değerlendirmektir. Bu amaç doğrultusunda aşağıdaki sorulara cevap aranmaktadır:

1. Yurtdışındaki üniversitelerde 2008-2018 yılları arasında İngilizce öğretiminde sanal gezinti uygulamaları kullanımıyla ilgili ne kadar tez çalışması yapılmıştır?

2. Yapılan çalışmaların yıllara göre dağılımı nasıldır?

3. Yapılan çalışmalarda kullanılan araştırma desenlerinin dağılımı nasıldır?

4. Yapılan çalışmalarda kullanılan veri toplama yöntemlerinin dağılımı nasıldır? 
5. Yapılan çalışmaların hedef kitlesinin dağılımı nasıldır?

$\mathrm{Bu}$ amaçlar doğrultusunda son 10 yılda, yurtdışında gerçekleştirilmiş İngilizce öğretiminde sanal gezinti kullanımını konu edinen lisansüstü tez çalışmaları taranarak, sanal gezinti uygulamalarının İngilizce öğretiminde kullanımı çeşitli değişkenler açısından değerlendirilmeye çalışılmıştır.

\section{Araştırmanın Sayıltıları}

1. Araştırma için taranan tezler, İngilizce öğretiminde sanal gezinti uygulamaları kullanımının dil becerileri üzerindeki etkisini yansıtmaktadır.

2. Araştırma için taranan tezler, İngilizce öğretiminde sanal gezinti uygulamaları kullanımının öğrenci başarısı üzerindeki etkisinin değerlendirilmesini yansıtmaktadır.

3. Araştırma için taranan tezler, İngilizce öğretiminde sanal gezinti uygulamaları kullanımının hedef kitle görüşleri açısından değerlendirilmesini yansıtmaktadır.

\section{Araştırmanın Sınırlılıkları}

1. Bu çalışma İngilizce öğretiminde sanal gezinti uygulamaları kullanımıyla sınırlıdır.

2. $\mathrm{Bu}$ amaçla, veri toplama ve verilerin analizinde İngilizce öğretiminde sanal gezinti uygulamaları kullanımı üzerine yapılan çalışmalardan elde edilen nicel ve nitel veriler kullanılmıştır.

3. Bu çalışma 2008-2018 yılları arasındaki yabancı tezlerle sınırlıdır.

\section{Yöntem}

Bu çalışma, İngilizce öğretiminde sanal gezinti uygulamaları kullanımını konu edinen yurtdışında gerçekleştirilmiş lisansüstü tez çalışmalarını değerlendirmek amacıyla desenlenmiş bir meta-sentez çalışmasıdır. Meta-sentez, aynı konu üzerine yapılan çalışmaların temalar veya ana şablonlar oluşturularak eleştirel bir bakış açısıyla yorumlanması ve sentezlenmesi sürecidir (Polat, 2017). Farklı araştırmacılar (Lincoln ve Guba, 1985; Noblit ve Hare, 1988), meta-sentezi veri kaynağı olarak hem nitel hem de nicel araştırmaları kullanan nitel bir araştırma yöntemi olduğunu ve yorumlayıcı bir niteliği barındırdığını belirtmişlerdir. Nitel bir araştırma deseni olan meta sentez araştırma yöntemi, nicel ve nitel araştırma bulgularını yorumlamak için önceden belirlenen ve/veya verilerin ortaya çıkardığı temalar ve şablonlar üzerinden bir sentez çalışması gerçekleştirmeyi kapsar (Atakan Duman ve Özdora Aksak, 2017). Neden ve etkileri çevreleyen sonuçların kesinliğini artırmayı amaçlayan ve çalışmalar arasında birleştirici olan nicel meta-analizden farklı olarak (Walsh ve Downe, 2005) meta-sentez, yorumlayıcıdır (Aküzüm ve Özmen, 2013). Ayrıca, nitel meta-sentezde asıl amaç, incelenen bütün çalışmaların daha geniş yorumlayıcı dönüşümlerini yaratmak ve her bir özel çalışmadaki yorumlayıcı dönüşümlere sadık kalmaktır (Sandelowski ve Barroso, 2003). Meta sentez yöntemi ile birçok araştırmanın bulguları incelenip yorumlanabilir (Thorne vd., 2004; Finfgeld, 2003; Strobel ve Barneveld, 2009; Aküzüm ve Özmen, 2013; Atakan Duman ve Özdora Aksak, 2017).

Çalışmada ayrıca meta-sentez yönteminin yanı sıra betimsel araştırma yöntemlerinden olan doküman incelemesi de kullanılmıştır. Doküman incelemesi nitel araştırmada doğrudan gözlem ve görüşmenin olanaklı olmadığ durumlarda kullanılan veya görsel materyallerin araştırmaya dâhil edilmesini temel alan bir yöntemdir (Nart, 2017). Doküman incelemesi, araştırılması hedeflenen olgu veya olaylar hakkında bilgi içeren yazılı materyallerin analizini kapsamaktadır (Yıldırım ve Şimşek, 2004). Belgesel tarama olarak da ifade edilen bu teknik, var olan kayıt ve belgelerin, veri kaynağı olarak sistemli incelenmesidir (Karasar, 2006).

\section{Verilerin Toplanması}

Meta-sentez yöntemi ile anlamlı ve geçerli sentez bulgulara ulaşılması için araştırma sorularına ilişkin birincil bulguların en az 10-12 birincil araştırmaya dayalı olması önerilmektedir (Sandelowski vd., 1997; Paterson vd., 2001; Jones, 2007; Bondas ve Hall, 2007; Poggenpoel ve Myburgh, 2008; Sözer ve Oral, 2016).

Türkiye'de sanal gezinti uygulamalarının İngilizce öğretiminde kullanımı üzerine yapılmış olan çalışma sayısı yeterli olmadığından, araştırmada kullanılacak olan çalışmalar yurtdışında çalışılmış yükseklisans ve doktora düzeyinde tezlerden oluşmaktadır. Araştırmada kullanılacak çalışmalar ProQuest Dissertations and Theses Global (ProQuest Doktora ve Yükseklisans Tez Merkezi)'dan internet aracılığıyla toplanmıştır.

Noblit ve Hare'in (1988) meta-senteze dahil edilecek olan çalışmalar hakkındaki kriterleri göz önüne alınarak aşağıdaki dahil edilme ölçütleri belirlenmiştir:

1. Çalışmanın 2008-2018 yılları arasında gerçekleştirilmiş olması.

2. Çalışmanın İngilizce öğretiminde sanal gezinti uygulamaları kullanımı üzerine olması.

3. Araştırmanın lisansüstü tezi olması.

4. Araştırma örnekleminin yurtdışında yapılmış çalışmalar olması. 
Yukarıda belirtilen dahil edilme kriterleri doğrultusunda meta-senteze dahil edilen tezlerin seçilmesine ilişkin anahtar kelimeler İngilizce sanal gerçeklik (virtual reality), virtual worlds (sanal dünyalar), English language teaching (İngilizce öğretimi) olarak belirlenmiş ve ProQuest Tez tarama Kataloğu'nda taranmıştır.

\section{Verilerin Analizi}

İngilizce öğretiminde sanal gezinti uygulamaları kullanımını konu edinen çalışmalardan elde edilen verilerin farklı özellikleri (araştırma modeli, veri toplama yöntemi, hedef kitle) yüzde ve frekans dağılımı şeklinde tablolarda belirtilmiştir. Araştırma kapsamında elde edilen verilerin analizi için SPPS 22 (Statistics Package for Social Sciences 22) paket programı kullanılmıştır.

\section{Bulgu ve Yorumlar}

Araştırma kapsamına dahil edilen tezlerin analizi tablolar halinde sunulmuştur.

Tablo 1. ProQuest Tez Tarama Kataloğunda Anahtar Kelimeler Kullanılarak Ulaşılan Tezlerin Yıllara Göre Dağılımı

\begin{tabular}{lcc}
\hline Tezlerin Yayımlanma Yil & f & \% \\
\hline 2008 & 0 & 0 \\
2009 & 0 & 0 \\
2010 & 1 & 10 \\
2011 & 1 & 10 \\
2012 & 0 & 0 \\
2013 & 2 & 20 \\
2014 & 2 & 20 \\
2015 & 0 & 0 \\
2016 & 2 & 20 \\
2017 & 2 & 20 \\
2018 & 0 & 0 \\
\hline Toplam & 10 & 100 \\
\hline
\end{tabular}

Tablo 1'de görüldüğ̈̈ üzere, 2008-2011 yılları arasında İngilizce öğretiminde sanal gerçeklik uygulamaları kullanımını konu edinen 10 adet lisansüstü tez çalışmasına bakıldığında 2008, 2009, 2012 ve 2018 yıllarında söz konusu uygulamalarla ilgili herhangi bir çalışma bulunamamıştır. Buna ek olarak, 2010 ve 2011 yıllarında yapılan çalışmaların her biri araştırmanın \%10'unu, 2013, 2014, 2016 ve 2017 yıllarında yapılımış olan çalışmaların her biri araştırmanın \%20'sini oluşturmaktadır.

Çalışma kapsamında elde edilen lisansüstü tezlerin araştırma yöntem ve desenleri incelenmiş ve elde edilen veriler doğrultusunda dağılımları Tablo 2'de verilmiştir.

Tablo 2. Lisansüstü Tezlerin Araştırma Modellerine Göre Dağılımı

\begin{tabular}{lcc}
\hline Araştırmanın Modeli & f & \% \\
\hline Nitel & 4 & 40 \\
Deneysel & 2 & 20 \\
Durum Çalışması & 4 & 40 \\
\hline TOPLAM & 10 & 100 \\
\hline
\end{tabular}

İngilizce öğretiminde sanal gerçeklik uygulamaları kullanımı konulu tezler incelendiğinde deneysel desen, nitel yöntem ve durum çalışması örneklerine eşit oranda (\%40) ve deneysel desen kullanılan çalışmalara yalnızca \%20 oranında rastlandığı görülmüştür. Buna ek olarak, bazı tez çalışmalarında araştırmacılar yalnızca araştırma modeline değinmiş ve araştırma deseninden söz etmemişlerdir.

Çalışma kapsamında elde edilen lisansüstü tezlere ait veri toplama yöntemleri incelenmiş ve elde edilen verilerin dağılımları Tablo 3’te verilmiştir. 
Tablo 3. Lisansüstü Tezlerin Veri Toplama Araçlarına Göre Dağılımı

\begin{tabular}{lcc}
\hline Veri Toplama Araçları & $\mathbf{f}$ & $\mathbf{\%}$ \\
\hline Anket & 4 & 18,18 \\
Başarı Testi & 2 & 9,09 \\
Gözlem & 3 & 13,64 \\
Görüşme & 7 & 31,82 \\
Doküman İnceleme & 4 & 18,18 \\
Videolar & 1 & 4,55 \\
Sohbet Kayıtları & 1 & 4,55 \\
\hline TOPLAM & 22 & 100 \\
\hline
\end{tabular}

Tablo 3 incelendiğinde en çok kullanılan veri toplama aracının görüşme $(\% 31,82)$, en az kullanılan veri toplama aracının ise videolar $(\% 4,55)$ ve sohbet kayıtları $(\% 4,55)$ olduğu belirlenmiştir. Çalışma kapsamında incelenen bazı tezlerde ise birden fazla veri toplama aracı kullanıldığı tespit edilmiştir.

Çalışma kapsamında elde edilen lisansüstü tezlerin hedef katılımcıları incelenmiş ve katılımcılara ait dağılım Tablo 4'te verilmiştir.

Tablo 4. Lisansüstü Tezlerin Hedef Katılımcılara Göre Dağılımı

\begin{tabular}{lcc}
\hline Hedef Katılımcılar & $\mathbf{f}$ & \% \\
\hline Öğretmenler & 3 & 30 \\
Öğrenciler & 7 & 70 \\
Hedef Katılımcı Yok & 0 & 0 \\
\hline TOPLAM & 10 & 100 \\
\hline
\end{tabular}

Tablo 4 incelendiğinde çalışma kapsamında incelenen lisansüstü tezlerde araştırmaya dahil edilen katılımcılar en fazla öğrenciler (\%70) olmuştur. Aynı zamanda araştırma kapsamında hedef katılımcıların bulunmadığı herhangi bir çalışmaya rastlanmamıştır.

Araştırma kapsamında incelenen tezlerden elde edilen bulgular aşağıda özetlenmiştir:

Jee (2010), İkinci Dil Olarak İngilizce Öğrenen Öğrencilerin Second Life'da Etkileşimi: Görev Temelli Olarak Senkronize Edilmiş Bilgisayar Temelli İletişim (ESL Students' Interaction in Second Life: Task-Based Synchronous Computer Mediated Communication) adlı bir doktora çalışması yürütmüştür. Araştırmacı, çalışma sonucunda öğrencilerin İngilizce derslerinde sanal gerçeklik uygulaması olan Second Life kullanımına olumlu baktıklarını ve aynı zamanda bu uygulamayı kullanarak yabancı dil konuşmada anlama, açıklama ve onaylama işlemlerini rahatlıkla yapabildiklerini belirtmiştir.

Kim (2011), Üç Boyutlu Sanal Dünya İle Bütünleşik Bir İngilizce Öğretim Programı İçin Öğretim Tasarımı (An Instructional Design for An Integrated English Language Curriculum With 3D Virtual World Affordances) adlı doktora tezinde üç ayrı okulda bulunan öğrencilere kendi hazırladığı modüllerden oluşan ve sanal gerçeklik uygulamalarını kullandığı bir İngilizce öğretimi gerçekleştirmiş ve araştırma sonucunda anadilleri Korece olan öğrencilerin İngilizce konuşmada ve diğer temel berecileri kullanmalarında akıcılık sağladığını tespit etmiştir.

Sanal Yabancı Dil Öğretmenleri, Öğrencilerin Sanal Okullarda Yabancı Bir Dil Öğrenebilmeleri İçin Çalışan Öğretim Uygulamaları Olarak Neler Söylüyor? (What Do Virtual Foreign Language Teachers Report As The Teaching Practices That Work So That Their Students Can Learn A Foreign Language In Virtual Schools?) adlı doktora tezinde ise McKeever (2013), sanal ortamların öğrencilere diyalog içeren tamamlayıcı öğretmen etkinlikleri sunduğundan ve aynı zamanda uygun içerik sanal bir ortamda sunulduğunda öğrencilerin hedef dilde konuşma becerilerini rahatlıkla kullanabildikleri sonucuna ulaşmıştır.

Abal (2013), Normal Sınıf ve Çok Kullanıcılı Sanal Ortamların, Yetişkinlerin Ortaöğretim Sonrası İngilizce Öğrenenlerin Algılanan Konuşma Kaygıları Üzerindeki Etkilerinin Karşılaştırılması (A Comparison of The Effects of Classroom and Multi-User Virtual Environments On The Perceived Speaking Anxiety of Adult PostSecondary English Language Learners) adlı 5'i kontrol, 6'sı deney grubunda bulunan toplam 11 öğrenci üzerinde 10 hafta boyunca uyguladığı deneysel çalışmada, anadili İngilizce olan kişilerle sanal sınıflar aracılığ 1 ile görüşme yapan deney grubu öğrencilerinin İngilizce konuşma kaygılarında yüz yüze konuşma dersleriyle İngilizce dersi işleyen kontrol grubuna göre daha fazla bir azalma olduğunu saptamıştır. 
Aldosemani (2014), İngilizce Öğrenenlerin Kültürlerarası Etkileşimlerinin Üçüncü Mekanı Olan Second Life (Second Life As Third Place For ELL's Cross Cultural Interaction) adlı, Uluslararası Öğrenci Değişim ve Burs Programı kapsamında en az altı ay boyunca İngilizce öğrenen ve yabancı dil öğrenmede altıncı seviyede olan 6 Arap ve bu altı öğrencinin görüşme yaptığı 4 Amerikan olmak üzere toplam 10 katılımcıyla gerçekleştirdiği çalışmasında öğrencilerin sanal gezinti turların kullanıldığı çeşitli çalıştaylar ve eğitimlere katılımlarını gözlemlemiștir. Bu çalıșma sonunda, Amerikalı bir diğer ifadeyle İngilizce'yi anadili olarak kullanan öğrencilerle etkileşim halinde olan öğrencilerin görüşleri alınmıştır. Bu görüşler doğrultusunda araştırmacı, katılımcıların bir sanal gezinti uygulaması olan Second Life uygulaması üzerinden Amerikan öğrencilerle gerçekleştirdikleri etkileşimin Arap öğrencilerin, Amerikan öğrencilerin kültürel bilgileri ve anlayışları hakkında bilgilerinin arttığını ve aynı zamanda dil becerilerinde bariz bir gelişme olduğunu ifade ettiklerini belirtmiştir.

Baldwin (2014), on altı hafta boyunca altı katılımcıyla gerçekleştirdiği, Üç Boyutlu Bir Sanal Ortamda Meydana Gelen Bir Orta Batı Üniversitesi İngilizce Yazma Kursunun Uluslararasılaşması İle İlgili Bir Durum Çalışması (A Case Study of The Internationalization of A Midwestern University English Composition Course Occurring in A 3-D Virtual Environment) adlı çalışmasında, katılımcıların dil becerilerinde özellikle İngilizce yazma becerisinde sanal gezinti uygulaması olan Second Life'ın olumlu yönde bir etkisi olduğundan ancak katılımcıların küresel farkındalık ve uluslararası etkinliklerde düşük düzeyde bir ilgiye sahip olduklarından söz etmiştir.

Scanlon (2016), En İyi Uygulamaların Delphi Çalışması: Sanal Dünyalarda Yabancı Dil Eğitimi İçin Bir Öğretim Tasarımı (A Delphi Study of Best Practices: Instructional Design for Foreign Language Education in Virtual Worlds) adlı çalışmasında Delphi tekniği kullanılarak İngilizce öğretiminde sanal gezinti uygulamaları kullanılarak kullanılabilecek bir öğretim tasarımının olup olmaması gerektiğine yönelik bir anket geliştirme çalışması yapmış, aynı zamanda bu anketi öğretmenlere uygulayarak İngilizce öğretiminde sanal gezinti uygulamalarının kullanılıp kullanılmaması gerektiğine karar vermeye çalışmışıı. Bu araştırma sonucunda yazar, sanal dünyaların çok ortamlı bağlamlara sahip, simgeler açısından zengin, öğrencilerin avatarlar alarak yabancı dil öğrenme süreçlerinde etkin olabilecekleri olanaklara sahip olabileceğini, aynı zamanda öğrencilerin kendilerine olan güvensizlikleri ve yabancı dil öğrenme kaygısını en az düzeye indirebileceği, sorun temelli, beceri temelli ve deneyimsel öğrenmeyi de destekleyebileceği sonucuna ulaşmıştır.

İngilizce'yi belirli amaçlar için öğrenenlere (ESP) içerik temelli İngilizce modelini sanal dünyalar üzerinde kullanarak öğretme amacıyla gerçekleştirdiği ve 16 katılımcıyı dahil ettiği Dilin Ötesinde Öğrenme: Belirli Amaçlar İçin İngilizce (ESP) Öğrenenlerin Second Life ${ }^{\circledR}$ Dünyasında Edindiği Deneyim (Learning Beyond Language: English for Specific Purposes (ESP) Learners' Experience in The Second Life ${ }^{\circledR}$ World) adlı çalışmasında Li (2016), İngilizce öğrenme süreçlerinde henüz yeni başlayan öğrencilerin sanal dünyalara karşı olumlu bir tutum sergilediklerini belirtmiştir. Araştırmacı aynı zamanda, katılımcıların sanal dünyaların kullanımıyla işlenen İngilizce derslerinde daha fazla katılım sağladıklarını, öğrencilerin kendi öğrenmelerini yönetebildiklerini belirtmiştir.

Cypris Köyü: Sanal Dünyalarda Dil Öğrenme (Cypris Village: Language Learning in Virtual Worlds) adlı çalışmasında DuQuette (2017), bir sanal gezinti uygulaması olan Second Life portalı üzerinde bulunan ve İngilizce öğretimi için tasarlamış olan Cypris Köyü'nün Aralık 2008'den beri nede bu kadar etkin bir şekilde kullanıldığını araştırmıştır. Araştırma sonucunda yazar, öğrencilerin İngilizce öğrenirken ders işledikleri Cypris Köyü’nde gerçekleştirdikleri eylemlerin kendi yaşantılarına çok benzer olduklarını, grup çalışmasıyla dil uygulamalarını çok rahatlıkla yapabildiklerini, ve çok ortamlı bir öğrenmenin gerçekleştiğini söylediklerini belirtmiştir.

Sanal Gerçeklik Oyun Sınıfı Uygulaması: Öğretmen Bakış Açıları ve Öğrenci Öğrenme Çıktıları (Virtual Reality Game Classroom Implementation: Teacher Perspectives and Student Learning Outcomes) adlı çalışmasında Alfadil (2017), bir sanal dünya uygulaması olan House of Languages (Diller Evi)'nin öğrencilerin İngilizce kelime öğrenmelerine olan etkisini belirlemeyi amaçlamıştır. 64 ögrencinin deney ve kontrol grubunu oluşturduğu çalışmada yazar, iki haftalık bir deney sürecinde haftada dört saat ders olmak üzere toplam her bir grup için sekizer saat ders uygulaması yapmışıtır. Deney grubu öğrencileri İngilizce derslerini Diller Evi uygulamasını kullanarak alırken, kontrol grubu öğrencileri yüz yüze öğretim gerçekleştirmiştir. Deneysel süreç sonunda uygulanan başarı testinden elde edilen verilere göre Diller Evi uygulamasını kullanan deney grubu öğrencilerinin İngilizce kelime öğrenmede yüz yüze öğretim gören öğrencilere göre daha fazla bir başarı sergiledikleri görülmüştür.

\section{Tartışma ve Sonuç}

Çalışma kapsamında incelenen tezlerde en fazla kullanılan modelin durum çalışması ve nitel desen olduğu görülmüştür. En az kullanılan yöntem ise nicel yöntem desenlerinden deneysel desen olarak belirlenmiştir. 
Araştırma kapsamında incelenen tezlerde en çok kullanılan veri toplama yöntemi görüşme olarak bulunmuştur. Bazı çalışmalarda, çalışmanın etkinliğini artırmak için birden fazla veri toplama yöntemine yer verilmiştir. Çalışmalar içerisinde deneysel desenin az kullanılmasından dolayı veri toplama araçlarından en az kullanılanı başarı testleri olmuştur. Bunun yanı sıra videolar ve sohbet kayıtlarının da en az kullanılan veri toplama araçları olduğu görülmüştür.

Çalışma, hedef katılımcı grupları açısından incelendiğinde, yapılan çalışmaların en fazla öğrencilerle gerçekleştirildiği görülmektedir. Tez içerikleri incelendiğinde İngilizce öğretiminde sanal gezinti uygulamaları olarak en çok Second Life portalının kullanıldığı görülmektedir. Bu durumun nedeni ise Second Life portalının erişiminin her yerden sağlanabilmesi, hesap edinmenin ücretsiz olması, sanal sınıflar kurabilme olanağı tanıması olabilir. Aynı zamanda başka sanal gezinti portallarının kullanılmaması ya da az kullanılmış olması bir önceki ifadede belirtildiği gibi hesap oluşturmanın ücretli olması, sanal ortamda yabancı dil sınıfları kurabilme özelliğinin bulunmaması, uygulamalara her yerden erişimin sınırlı olması, uygulamayı üreten şirketlerin uygulama üzerinde gerçekleştirdikleri güncellemeler, her uygulamanın her bilgisayarda açılmaması nedeniyle olabilir.

Yurtdışında yapılmış ve bu çalışma kapsamında incelenen lisansüstü tez sonuçlarına baktığımızda genel olarak sanal gezinti uygulamalarının İngilizce öğretimine olumlu katkılar sağladığı belirlenmiştir. Bunun yanı sıra, çalışmalarda kullanılan sanal gezinti uygulamaları kullanılarak oluşturulan öğrenme etkinliklerine bakıldığında yalnızca öğrenci başarısı üzerine odaklanılmadığı, aynı zamanda öğrenci ve öğretmen görüşlerine yer verildiği de görülmüştür. Ayrıca, araştırmacılar çalışmaları doğrultusunda kullanılan sanal gezinti turlarının belirli dil becerileri açısından incelenmesinin yanında bu uygulamaların öğrencilerin kaygı düzeylerini de ne şekilde etkilediğini belirlemeye çalışmışlardır. Buna ek olarak, araştırma kapsamında incelenen çalışmalarda kullanılan sanal gezinti uygulamalarının öğretmenlerin mesleki gelişim etkinlikleri için kullanıldığı da belirlenmiş ve ayrıca sanal gezinti uygulamalarının İngilizce derslerinde kullanılıp kullanılmaması yönünde bir de anket geliştirme çalışması yapılmıştır. Yapılan bu anket geliştirme çalışmasında katılımcılar, İngilizce derslerinde kullanılacak sanal gezinti uygulamalarının İngilizce dört temel beceriyi (dinleme, konuşma, okuma ve yazma) içeren etkinlikleri sağlayacak şekilde tasarlanması gerektiğini belirtmişlerdir.

\section{Öneriler}

Bu çalışma İngilizce öğretiminde sanal gezinti uygulamaları kullanımını incelemek amacıyla gerçekleştirilmiştir. Ancak, artıılmış gerçeklik uygulamalarının yabancı dil öğrenme becerilerine olan etkisini araştııılabileceği gibi, sanal gezinti uygulamalarına benzer bir şekilde sanal gerçeklik uygulamalarının da dil öğretiminde kullanımı incelenebilir. Ayrıca, ülkemizde de İngilizce öğretiminde sanal uygulamaların kullanımı yaygınlaştırılarak bu konuda yapılmış olan lisansüstü çalışmalar da incelenebilir.

\section{Kaynakça}

Abal, A. (2013). A comparison of the effects of classroom and multi-user virtual environments on the perceived speaking anxiety of adult post-secondary English language learners. Yayımlanmamıs doktora tezi, Florida International University, Miami, Florida.

Achille, C., Fassi, F., Fiorillo, F., Mandelli, A., Rechichi, F., and Teruggi, S. (2016). VR for cultural heritage: A VR-WEB-BIM for the future maintenance of Milan's Cathedral.

Aküzüm, C., ve Özmen, F. (2013). Eğitim denetmenlerinin rollerini gerçekleştirme yeterlikleri bir meta-sentez çalışması. EKEV Akademi Dergisi, 17(56), 97-120.

Aldosemani, T. I. (2014). Second Life as third place for Ells' cross-cultural interaction. Yayımlanmamış doktora tezi, University of Wyoming, Wyoming.

Alfadil, M. M. (2017). Virtual Reality Game Classroom Implementation: Teacher Perspectives and Student Learning Outcomes. Yayımlanmamış doktora tezi, University of Northern Colorado, Greeley, Colorado.

Atakan Duman, Ş., ve Özdora Aksak, E. (2017). Türkiye'de kurumsal sosyal sorumluluğun kavramsallaştırılması: meta sentez analizi, Business and Economics Research Journal, 8(3), 501-517.

Baldwin, N. J. (2014). A case study of the internationalization of a midwestern university English composition course occurring in a 3-D virtual environment. Yayımlanmamış doktora tezi, University of Missouri, Kansas.

Barkand, J., and Kush, J. (2009). GEARS a 3D virtual learning environment and virtual social and educational world used in online secondary schools. Electronic Journal of e-Learning, 7(3), 215-224. 
Black, R. W. (2005). Access and affiliation: The literacy and composition practices of English language learners in an online fanfiction community. Journal of Adolescent and Adult Literacy, 49(2), 118-128.

Bondas, T. and Hall, E. O. C. (2009). A decade of metasynthesis research in health sciences: A meta-method study, International Journal of Qualitative Studies on Health and Well-being, 2(2), 101-113.

Carruthers, H. P. C. (2013). Effect of the affordances of a virtual environment on second language oral proficiency. Yayımlanmamış doktora tezi, Southern Illinois University at Carbondale.

Chambers, A. (2010). Computer-assisted language learning: Context and conceptualization', Language Teaching, 43(1), 113-122.

Coleman, D. W. (2002). On foot in SIM CITY: Using SIM COPTER as the basis for an ESL writing assignment. Simulation \& Gaming: An Interdisciplinary Journal, 33, 217-230.

Deutschmann, M., Panichi, L., and Molka-Danielsen, J. (2009). Designing oral participation in Second Life - a comparative study of two language proficiency courses, ReCALL, 21(2), 206-229.

Dickey, M. D. (2005). Three-dimensional virtual worlds and distance learning: Two case studies of active worlds as a medium for distance education, British Journal of Educational Technology, 36(3), 439-451.

DuQuette, J. P. (2017). Cypris Village: Language Learning in Virtual Worlds. Yayımlanmamış doktora tezi, Temple University, Philadelphia, Pennsylvania.

Finfgeld, D. L. (2003). Metasynthesis: The state of the art-so far, Qualitative Health Research, 13(7), 893-904.

Garcia-Ruiz, M. A., Edwards, A., and Aquino-Santos, R. (2007). An online collaborative virtual reality environment for promoting listening comprehension., http://fel.uqroo.mx/adminfile/files/memorias/ Articulos_Mem_FONAEL_III/Garcia_Ruiz_Miguel_Angel_et_al.pdf web adresinden 23 Aralık 2018 tarihinde alınmıştır.

Gump, A. W. (2015). Facilitating Motivation in a Virtual World Within a Second Language Acquisition Classroom. Yayımlanmamış doktora tezi, University of South Florida.

Henderson, M., Huang, H., Grant, S. and Henderson, L. (2009). Language acquisition in second life: Improving self-efficacy beliefs. Proceedings of the 26th Annual ASCILITE International Conference, 2009. Auckland, New Zealand: ASCILITE.

Henderson, M., Huang, H., Grant, S. and Henderson, L. (2012). The impact of Chinese language lessons in a virtual world on university students' self-efficacy beliefs, Australasian Journal of Educational Technology, 28(3), 400-419.

Jacobson, I. (1993). Welcome to the virtual world. In R. Swadley (Ed.). On the cutting edge of technology, Carmel, IN: Sams, 69-79.

Jee, M. J. (2010). ESL students' interaction in Second Life: Task-based synchronous computer -mediated communication. Yayımlanmamış doktora tezi, The University of Texas a Austin, Austin, Texas.

Jones, L. M. . (2007). Overview of methods. In C. Webb \& B. Roe (Eds.), Reviewing research evidence for nursing practice: Systematic reviews, London: Blackwell, 63-72.

Karasar, N. (2006). Bilimsel araştırma yöntemi. (16.Basım). Ankara: Nobel Basımevi.

Kim, S. H. (2011). An instructional design for an integrated English language curriculum with 3D virtual world affordances. Yayımlanmamış doktora tezi, The University of Wisconsin, Wisconsin, Madison.

Lam, W. S. E. (2000). L2 literacy and the design of the self: A case study of a teenager writing on the internet, TESOL Quarterly, 34(3), 457-481.

Li, F. (2016). Learning beyond language: English for specific purposes (ESP) learners' experience in the Second Life ${ }^{\circledR}$ World. Yayımlanmamış doktora tezi, The University of Alabama, Tuscaloosa, Alabama.

Lincoln, Y. S. and Guba, E. G. (1985). Naturalistic Inquiry. Newbury Park, CA: Sage Publications.

McKeever, L. B. (2013). What do virtual foreign language teachers report as the teaching practices that work so that their students can learn a foreign language in virtual schools? Yayımlanmamıs doktora tezi, Capella University, Minneapolis, Minnesota. 
McLellan, H. (2004). Virtual realities. In D. H. Jonassen (Ed.), Handbook of research for educational communications and technology, Mahwah, NJ: Lawrence Erlbaum Associates, 461-497.

Nart, S. (2017). 2000-2016 yılları arasında Türkiye'de yazılmış ses eğitimi konulu lisansüstü tezlerin incelenmesi, Ĕ̈itim ve Öğretim Araştırmalarl Dergisi, 4(6), 231-243.

Noblit, G.W. and Hare, R. D. (1988). Meta-ethnography: Synthesizing qualitative studies. Newbury Park, CA: Sage.

Paterson, B., Thorne, S., Canam, C. and Jillings, C. (2001). Meta-study of qualitative health research. Thousand Oaks, CA: Sage.

Peterson, M. (2006). Learner interaction management in an avatar and chat-based virtual world, Computer Assisted Language Learning, 19(1), 79-103.

Peterson, M. (2010). Learner participation patterns and strategy usage in Second Life: An exploratory case study, $\operatorname{ReCALL}, 22(3), 429-439$.

Poggenpoel, M. ve Myburgh, C. P. H. (2008). A Meta-synthesis of completed qualitative research on learners` experience of aggression in secondary schools in South Africa, International Journal of Violence and School, 8, 60-84.

Polat, M. (2017). Türkiye'de öğrenciler neden kopya çeker? Bir meta-sentez çalışması, Ĕ̆itim Bilimleri Araştırmaları Dergisi, 7(1), 223-242.

Ranalli, J. (2008). Learning English with the Sims: Exploiting authentic computer simulation games for L2 learning, Computer Assisted Language Learning, 21(5), 441-455.

Sandelowski, M., Docherty, S. and Emden, C. (1997). Qualitative meta synthesis: Issues and techniques, Research in Nursing \& Health, 20(4), 365-371.

Sandelowski, M. and Barroso, J. (2003). Toward a metasynthesis of qualitative findings on motherhood in HIVpositive women, Research in Nursing \& Health, 26, 153-170.

Scanlon, T. (2016). A Delphi Study of Best Practices: Instructional Design for Foreign Language Education in Virtual Worlds. Yayımlanmamış doktora tezi, Northcentral University, Scottsdale, Arizona.

Sözer, Y. ve Oral, B. (2016). Sınıf içi öğrenmeleri destekleyen okul dışı aktif öğrenme süreci: bir meta-sentez çalışmas1, International Journal of Eurasia Social Sciences, 7(22), 278-310.

Stevenson A. and Lindberg C. A. (2015). New Oxford American Dictionary. (3rd edition). Oxford University Press.

Strobel, J. and van Barneveld, A. (2009). When is PBL more effective? A Meta-synthesis of meta-analyses comparing PBL to conventional classrooms, Interdisciplinary Journal of Problem-Based Learning, 3(1), 44-58.

Thorne, S. E., Jensen, L., Kearney, M. H., Noblit, G.W. and Sandelowski, M. (2004). Qualitative meta synthesis: Reflections on methodological orientation and ideological agenda, Qualitative Health Research, 14(10), 1342-1365.

Von Der Emde, S., Schneider, J. and Kotter, M. (2001). Technically speaking: Transforming language learning through virtual learning environments (MOOs), Modern Language Journal, 85(2), 210-225.

Walsh, D. and Downe, S. (2005). Meta-synthesis method for qualitative research: A literature review, Journal of Advanced Nursing, 50(2), 204-211.

Warschauer, M. and Healey, D. (1998). Computers and language learning: An overview, Language Teaching, 31, 57-71.

Yamazaki, K. (2015). Learning to Communicate in a Virtual World: The Case of a JFL Classroom, Yayımlanmamış doktora tezi, The University of Toledo.

Yıldırım, A. ve Şimşek, H. (2004). Sosyal bilimlerde nitel araştırma yöntemleri. (4.Baskı). Ankara: Seçkin Yayınevi.

Yi, Y. (2008). Relay writing in an adolescent online community, Journal of Adolescent \& Adult Literacy, 51(8), 670-680. 
Zheng, D., Young, M. F., Wagner, M. M. and Brewer, R. A. (2009). Negotiation for action: English language learning in game-based virtual worlds, The Modern Language Journal, 93(4), 489-511.

\section{Extended Abstract}

Virtual reality, also called the virtual world by Henderson et al. (2009), is a computer technology that gives users illusion in a virtual environment (Alfadil, 2017). Stevenson and Lindberg (2015) described it as a computergenerated simulation of a three-dimensional image or environment that can interact in real or physical form by a person using special electronic equipment, such as a helmet with a screen or gloves equipped with sensors, in virtual reality. There is a new field of literature that discusses the potential benefits of virtual worlds, particularly with regard to teaching English (Abal, 2013). For example, Von Der Emde et al. (2001) suggested that virtual worlds for teaching English provide students with the ability to contextualize language use as part of cultural and social interaction.

Carruthers (2013) mentions that research about virtual environments in foreign language teaching is limited, and in addition to these findings, different researchers (Garcia-Ruiz et al., 2007; Ranalli, 2008; Zheng et al., 2009) reported that there are very few empirical studies indicating their benefits and effects on language development. From a small number of existing studies (Barkand and Kush, 2009; Peterson, 2006; Zheng et al., 2009) it has been found that virtual environments provide an improved learning environment. In our country, the number of studies on virtual reality applications in teaching English is quite limited. Therefore, this study is important in terms of examining the effects of the use of virtual reality applications on language teaching in terms of various variables.

The general aim of this study is to evaluate the postgraduate theses on the use of virtual reality applications in teaching English abroad. In line with this aim, it has been tried to determine how many theses have been done on the use of virtual reality applications in English language teaching between the years 2008-2018 in the universities abroad, the distribution of the studies done according to the years, the distribution of the research designs used in the studies, the distribution of the data collection methods used and the target population of the studies. In line with these objectives, graduate theses on the use of virtual reality in English teaching abroad in the last 10 years have been searched and the use of virtual reality in English language teaching has been tried to be evaluated in terms of various variables.

It has been determined that ten theses carried out abroad between 2008 and 2018 were carried out in 2010-2017. In addition to this, it was also seen that the most used model in the theses examined within the scope of the study was case study and qualitative designs. The least used method was determined as experimental design from quantitative methods. The most commonly used data collection method in the theses examined in the scope of the research was found as interview. Some studies have included multiple data collection methods to improve the effectiveness of the study. Due to the low use of experimental design, achievement tests were the least used among the data collection tools. In addition, video and chat recordings were the least used data collection tools. 